\title{
Notas para una historia de la izquierda
}

\author{
Roberto Pittaluga
}

Universidad Nacional de La Pampa / Universidad Nacional de La Plata / Universidad de Buenos Aires

1

Bien podría decirse que en la tarea de escribir una "historia de la izquierda" ambos términos se enlazan críticamente: lo histórico sirve para desmontar la aparente unicidad de sentido y experiencia de la izquierda, a la par que dicha experiencia política ejerce su sospecha sobre una historiografía que, generalmente, la ha relegado o no ha estado a la altura de su gesta incluso cuando la hizo objeto central de su trama.

Precisamente, al historizar la izquierda, las versiones de lo que se ha puesto bajo ese nombre presentan un panorama tan diverso que parece dudosa su pertenencia a una misma familia política o su coherencia como categoría general de una orientación política. Una situación que se ha expuesto en los debates en torno a la conveniencia de tal denominación, sobre todo en las últimas décadas, luego de los giros neoliberales de la socialdemocracia y de la implosión de los socialismos reales. Y es que no hay más que observar las numerosas intervenciones y disensos que siguieron a la publicación del libro de Norberto Bobbio, Derecha e Izquierda, para darse cuenta de la relatividad que acompaña cualquier definición de ese término, izquierda. Como si no fuera posible aprehenderlo y fijarlo, darle algún significado definitivo. Probablemente esa imposibilidad de fijación resida en el ensamble de algunos de sus atributos, aquellos que nos per- miten acercarnos, si no a una definición, al menos a la comprensión general de los significados que moviliza ese nombre. Quisiera presentar aquí algunas reflexiones preliminares y fragmentarias en torno a aspectos o características que generalmente forman parte de la izquierda: un componente relacional, otro posicional y, en muchos casos, tal vez la mayoría, un componente identitario (asociado a formas de institucionalización).

2 En su origen político, ${ }^{1}$ la noción de "izquierda" se configuró en clave relacional, al tiempo que promovía una imaginación espacial de la política que aún perdura -como pertenencias a determinados "espacios políticos"-. ${ }^{2}$ La metáfora espacial no se limitó,

\footnotetext{
${ }^{1}$ Aunque la cuestión no parece estar saldada en la historiografía, la distinción izquierda y derecha como categorías de orientaciones políticas remite a la Asamblea Nacional Constituyente en la Francia de 1789 o 1790, y se difunde por Europa acompañando el proceso revolucionario. Sin embargo, es recién en la segunda mitad del siglo XIX cuando su uso se tornó más consistente como designación de las formulaciones ideológicas y las prácticas políticas de la clase obrera y de distintos movimientos de impugnación del orden social. A su vez, su difusión no alcanzó el mismo grado de adhesión en las distintas regiones del viejo continente.

${ }^{2}$ Además del uso corriente, existen elaboraciones conceptuales de la política moderna en términos de espacio.
} 
como suele decirse, al recinto parlamentario. Se espacializó también en la convergencia o confrontación entre la representación -ese espacio del Parlamento que Tocqueville llamaba a defender frente a la journée proletaria aquel 15 de mayo de 1848 porque de ello dependía la suerte de las clases burguesas y aristocráticas- y la democracia, esa aparición del demos en la calle o la barricada -presencia popular que, al decir de François Furet, ${ }^{3}$ desempeña una función "diferenciadora" en el interior de la representación parlamentaria en la Francia revolucionaria, sobre todo después de esa formidable movilización de las mujeres parisinas a Versalles en octubre de 1789-; ${ }^{4}$ desde entonces, cada journée provocará un desplazamiento en el espectro de la representación, realineando en su seno la izquierda y la derecha.

Así, el componente relacional de la izquierda, si se figura por medio de la ubicación de una partición en el espacio de la representación parlamentaria, también expresa una experiencia política excedente respecto de dicho régimen, la cual modifica no solo la distribución de roles y posiciones sino las ideas mismas y la lógica que sustentan la disposición del orden político. La carga de sentido político de las referencias espaciales en el ámbito de la representación -el eje horizontal, lo llama Bobbio- se correlaciona con la irrupción democrática en la calle -el eje vertical

\footnotetext{
Véase Roberto D’Alimonte, “Espacio político”, en Norberto Bobbio, Nicola Matteucci y Gianfranco Pasquino (dirs.), Diccionario de Política, México, Siglo XXI, 1991, pp. 530-533.

3 François Furet [1969], "La Francia revolucionaria (1787-1791)", en Louis Bergeron, François Furet y Reinhart Koselleck, La época de las revoluciones europeas, 1780-1848, Colección Historia Universal Siglo XXI, vol. 26, México, Siglo XxI, 1976, p. 33.

${ }^{4}$ Formidable por el protagonismo femenino -en los grabados populares de la época, que las muestran armadas, a caballo y arrastrando los cañones, puede leerse "Avantgarde des femmes", toda una definición política- pero también notable porque la intervención de la multitud produce en la misma acción una convergencia y una confrontación con la Asamblea.
}

entre gobernantes y gobernados, añade el italiano-, aunque esta última es más bien un tipo de intervención paradójica, como apuntó Jacques Rancière, que al mismo tiempo que transforma el espacio de la circulación callejera en espacio de manifestación configura un sujeto que es a la vez gobernante y gobernado.

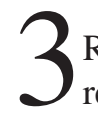
Resulta insuficiente limitar la dimensión relacional de la izquierda al ámbito de la representación parlamentaria y de los partidos. Porque las significaciones políticas de las referencias espaciales de la representación están, en principio, vinculadas a la emergencia de una nueva posición política que es exterior a ella. La dimensión posicional de la izquierda -también originaria- expresa una experiencia política que se nutre de la moderna emancipación de los sujetos de sus roles y lugares sociales prefijados; en particular, de aquella versión de la modernidad que se afirmaba en la potencia propia del mundo común e igualitario. Prefiero denominar como posicional esta dimensión de la izquierda para dar cuenta de sus orígenes emancipatorios, pues si atendemos a su etimología, el acto de emancipación implica "liberar algo o a alguien de una autoridad ella misma ligada a un derecho de propiedad", es decir, se trata de una acción por la cual el sujeto se desprende de la mano de quien lo aferra como posesión para dirigirse a una zona franca, de libertad, en la que ya no será poseído por nadie. ${ }^{5}$ La emancipación consiste, entonces, en un gesto de desplazamiento, de movimiento hacia una zona que se crea como libre, de abandono de la posición de sujeción originando un nuevo ordenamiento de las posiciones como también de las lógicas, los saberes y las percepciones del orden y la autoridad.

\footnotetext{
${ }^{5}$ Georges Didi-Huberman, Remontajes del tiempo padecido. El ojo de la historia, 2, Buenos Aires, Biblos, 2015, pp. 124-126.
} 
Como las mujeres emancipadas del siglo XVII, llamadas así despectivamente porque se habían sustraído a los mandatos sociales y eran autónomas y autosuficientes; como cuando los trabajadores, en las empresas recuperadas, asumen la organización de la producción y transforman ese espacio antes privado en uno de deliberación pública.

El aspecto posicional refiere a una subjetivación política que reconfigura tanto el orden -con sus lugares atribuidos para el ejercicio de la autoridad- como la racionalidad y la sensibilidad en las que se funda -y sus asociadas figuras de subjetividad-. Subjetivación que se manifiesta en acciones que dicen y en palabras que hacen; las denominadas "batallas simbólicas" en las revoluciones o en las revueltas emancipatorias no constituyen un elemento añadido sino que son inescindibles de esa misma politización. Apuntemos desde ahora que este elemento de "toma de la palabra" -como gustaba llamarlo José Sazbónresulta decisivo para la tarea historiográfica.

Las acciones de emancipación son también actos rememorativos, que recuperan tentativas pasadas, casi olvidadas. En el nombre "izquierda" paulatinamente se afirma un linaje histórico constituido por las referencias y el rescate de todos los actos emancipatorios pretéritos, pues el elemento posicional que caracteriza a la izquierda perdura en ella como marca originaria -en el sentido benjaminiano del origen-, de modo que la memoria de cada conato emancipatorio se actualiza en el que tenga lugar en un presente cualquiera. La izquierda, en cuanto posición, es también esa memoria de las emancipaciones pasadas. Los ejemplos son innumerables; mencionemos uno de estas latitudes, el de un Elías Castelnuovo que en un poema de 1919 vislumbra en la gesta revolucionaria en Rusia "los puños de Espartaco". ${ }^{6}$

${ }^{6}$ Elías Castelnuovo, "Los bárbaros están a las puertas de Petrogrado", en La Protesta, 26 de octubre de 1919, p. 2.
La multiplicidad de nombres que surgen con las experiencias de agencialidad política de les subalternes sugiere, por un lado, que el campo de lo que va reuniéndose bajo el genérico "izquierda" se caracteriza por la pluralidad. Y que incluso ese genérico, por estar internamente pluralizado, requiere de otras clasificaciones según los criterios relacionales y posicionales mencionados: como cuando se dice de un grupo o formación, o de las facciones o incluso de un argumento, que es de extrema izquierda, o izquierda moderada, reformista o revolucionaria, centro-izquierda, nueva izquierda, izquierda política o social, etcétera.

Si bien, como decía, en el concepto "izquierda" se reúnen experiencias y emergencias subjetivas vinculadas a dinámicas de la emancipación, sus derroteros posteriores pueden dar lugar a formaciones políticas en las que predomine el elemento identitario cuando cristalizan en institucionalizaciones más o menos estables que transforman un nombre inédito en una identidad. Incluso, esas trayectorias pueden resultar en inflexiones que reviertan las dinámicas emancipatorias aun conservando sus identificaciones relativas al universo simbólico-político de la izquierda. Ello permitía a Isaiah Berlin sostener que la Unión Soviética había usurpado el legado de la izquierda, haciendo estéril dicha categoría. ${ }^{7}$

Es plausible pensar que las derivas identitarias de los distintos nombres de la izquierda indican que las épocas de despolitización imponen a las acciones revolucionarias derrotadas modos de existencia adaptados al orden político hegemónico -de allí la preeminencia de criterios de representación adecuados a las lógicas políticas del Estado y que refuerzan

\footnotetext{
${ }^{7}$ Norberto Bobbio, Derecha e Izquierda. Razones y significados de una distinción política, Madrid, Taurus, 1995 , p. 33.
} 
por ello modalidades identitarias de carácter homogeneizante-. La dimensión identitaria se convierte en un dispositivo de homogeneización que abroga la pluralidad cuando la subjetivación política se sustancializa, se convierte en una identificación que ordena (en el doble sentido de mandato y clasificación). Como cuando "proletario" deja de ser un nombre político -como en el autorreconocimiento de Auguste Blanqui ante el juez en 1832- para transformarse en la designación de los asalariados; o cuando "comunismo" deja de ser el nombre del "movimiento real que viene a abolir el estado de cosas" y se convierte en la denominación de una de las fracciones partidarias de izquierda. ${ }^{8}$

De todos modos, se puede decir -con las excepciones que toda generalización conlleva- que las de izquierda han sido identidades blandas, pues aun en las más consistentes de esas formaciones existen tensiones y divisiones por medio de las cuales lo identitario es puesto permanentemente en crisis, como sucedía con el SPD alemán y sus orientaciones centristas, revisionistas, revolucionarias, cada una tratando de establecer las modalidades de acción y los sustentos conceptuales del gran movimiento socialdemócrata, pero, sobre todo, cada una siendo la expresión de formas de subjetividad diferentes y hasta antagonistas. Aun institucionalizaciones más rígidas, con fuerte fidelidad identitaria, como los par-

\footnotetext{
${ }^{8}$ La problemática de lo identitario ha sido abordada desde disciplinas y marcos teóricos muy variados, como el psicoanálisis, trabajos sobre memoria, la lingüística y el análisis del discurso, las teorías de género, los estudios poscoloniales, por nombrar algunos. Aquí me estoy refiriendo, simplificadamente, a un tipo de construcción (simbólica, narrativa, etc.) de la subjetividad, que la normaliza en torno a algunos parámetros fijados en el orden de lo evidente (que es también, sabemos, una construcción), parámetros que permiten sostener y fortalecer una institución y a la vez integrarla en el régimen racional y sensible hegemónico; se trata de dispositivos que relegan o subsumen la dinámica performativa de lo identitario.
}

tidos comunistas, exhiben trayectorias marcadas por rupturas, alejamientos, expulsiones, fracciones. ${ }^{9}$ En la mayoría de los casos, esas disidencias se presentan como momentáneos y pequeños desvíos respecto de las lógicas militantes y las subjetividades partidarias, como actos imperceptibles, no pensados como contrapuntos a las orientaciones de la organización o la corriente a la que se adhiere, como acciones y palabras que no se perciben cuestionando las identidades asumidas. Pero en las épocas de politización, esas tensiones latentes emergen con fuerza, como se observa en los agitados años '60, con la Nueva Izquierda/New Left, que en muchos casos eran inicialmente escisiones de la "izquierda tradicional". Movimientos que asumen nombres que se ubican en el universo político de la izquierda pero que pretenden diferenciarse de las nominaciones institucionalizadas, y que en no pocos casos producirán el mismo tipo de deriva identitaria y partidaria, soportando a su vez el mismo tipo de disidencias y escisiones. Las identidades en la izquierda parecen estar siempre en tensión, precisamente porque su valor posicional no cede completamente frente a esas dimensiones identitarias.

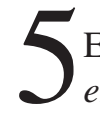
En 1920, Lenin publica El izquierdismo, enfermedad infantil del comunismo. Casi cinco décadas después, en 1968, los hermanos Cohn-Bendit editan Le gauchisme, reméde à la maladie sénile du communisme, invirtiendo paródicamente la carga: la intervención se mantiene en la misma tradición pero produce una diferenciación respecto del devenir del "comunismo", convertido en "par-

\footnotetext{
${ }^{9}$ Mencionemos como ejemplo el del Partido Comunista de la Argentina, el cual prácticamente no tuvo década en la que no debiera enfrentar disidencias de distinta envergadura. Otro asunto, cualitativamente diferente -que por cuestiones de extensión no podemos tratar aquí- es cuando la izquierda se hace Estado.
} 
tidos comunistas". ${ }^{10}$ El ejemplo sirve para recordar que una historia de la izquierda no es tanto una historia de las identidades políticas de la izquierda, de sus formalizaciones y/o corrientes reunidas bajo una misma denominación, sino la historia de sus diferenciaciones, de los desvíos, de la proliferación de nombres -antiguos y nuevos-. En todo caso, se trata de indagar cómo esas diferenciaciones devinieron, cuando lo hicieron, identidades.

Tanto o más que historia de organizaciones, grupos, personajes o etapas -aunque tampoco puede prescindirse de estos aspectos que explican las perdurabilidades a pesar de las tensiones, conflictos y subjetivaciones-, pienso que la historia de la izquierda es una historia de subjetivaciones políticas, de posiciones emancipatorias, de politizaciones a contrapelo del orden social pero también de muchos aspectos del orden formalizado de la misma izquierda.

Precisamente por esto último, historizar "la izquierda" impone, además, el examen de todas aquellas acciones, subjetivaciones, discursos, experiencias que sin identificarse con los nombres de la izquierda constituyen tentativas de orientación emancipatoria; la investigación histórica de la izquierda es así entendida en sus vínculos íntimos con diversas experiencias históricas, conceptuadas en términos como democracia, revolución, igualdad, libertad, etcétera.

El campo de la izquierda se trama entonces de al menos dos modos. Por un lado, está el mapa de sus particiones identitarias, de sus organizaciones partidarias, de sus formaciones y sus prácticas normalizadas. Por otro lado, su radiografía de posiciones difusas o dispersas, ocultas o latentes, memorias de

\footnotetext{
${ }^{10}$ Vale anotar que enragés es uno de los nombres elegidos por este gauchisme, lo que revela que las politizaciones siempre implican, como decíamos más arriba, rememoraciones de pasados intentos emancipatorios, que al actualizarse significan y potencian las acciones del presente.
}

acciones emancipatorias pasadas que fundamentan originariamente los nombres y las expectativas de las izquierdas. Tramas no coincidentes que involucran orientaciones y prácticas políticas las más de las veces divergentes, aun antagonistas. La tarea historiográfica se enfrenta así a la problemática constructiva de ambas tramas y de sus relaciones de convergencia o antagonismo, al análisis de los fundamentos de las distintas formaciones y formalizaciones de las corrientes de izquierda frente al examen de las significaciones y las concepciones en torno a prácticas, acciones o a núcleos políticoconceptuales que las subvierten y que configuran un campo de polaridades distinto, haciendo inteligible otro "ordenamiento" de "la izquierda". Se puede mencionar, como uno de los tantos ejemplos, la coexistencia y confrontación, más o menos abierta, de conceptualizaciones y prácticas en torno a la temporalidad histórica -sobre todo en momentos de álgida lucha y conflicto, pero no solo- como elementos configurativos de tramas antagonistas en la izquierda, elementos que constituyen tipos diferentes y divergentes de izquierda. ${ }^{11}$

\section{6} La historia es una historia de conflictos. Conflictos que involucran -entre otros ámbitos- su escritura, es decir, la historiografía. Sospecha de la izquierda: si la historiografía hegemónica, precisamente por serlo, normaliza la historia desde el punto de vista de los vencedores, ¿cómo se escribe una historia de la izquierda que dé cuenta de los ven-

\footnotetext{
${ }^{11}$ Me permito mencionar, para quienes tengan interés, mi investigación de estas dos tramas en la izquierda de la Argentina tal como se expresaron durante la primera posguerra y la década de 1920; Roberto Pittaluga, Soviets en Buenos Aires. La izquierda de la Argentina ante la revolución en Rusia, Buenos Aires, Prometeo Libros, 2015.
} 
cidos y por ello de los olvidados? Silencing the Past. Power and the Production of History tituló su libro Michel-Rolph Trouillot, obra en la que exhibe, entre otras cosas, cómo puede ser ocultado un fenómeno histórico -la revolución haitiana- incluso cuando se lo nombra. En la tesis XII, Benjamin apuntaba: "El sujeto del conocimiento histórico es, por supuesto, la clase oprimida que lucha". ${ }^{12} \mathrm{El}$ sujeto y el conocimiento son parte del conflicto de la historia; la historiografía como práctica está inscripta en y atravesada por la contienda. Para ganar en esa batalla que es la historia se debe también triunfar en la representación de la historia, en su concepción y en su escritura -como también alegoriza el filósofo judeoalemán en la primera tesis-. La conflictividad es inherente al sujeto del conocimiento, a las prácticas del historiador o la historiadora y a la misma arquitectura epistemológica de la historia.

Hace falta, entonces, preguntarnos por aquella historiografía que posibilita explicar y comprender la historia desde la perspectiva de las emancipaciones, logradas y derrotadas, y sobre todo desde estas últimas. Interrogarnos por el conflicto en la historia y en la historiografía implica examinar y replantear sus métodos, sus archivos, sus modalidades escriturarias, sus instituciones, los procedimientos de la transmisión, aun sus conceptos, muchos de ellos ya naturalizados. Entraña a su vez una crítica sobre los mismos modos de construcción histórica y de interpretación de los restos de las gestas de los oprimidos. Una operación que involucra desplegar una mirada capaz de despojar a la realidad de aquello que tiene de evidente y que está producido como sentido antes de su interpretación, y a la par elaborar un régimen de legibilidad de los res-

\footnotetext{
${ }^{12}$ Walter Benjamin [1940], "Sobre el concepto de historia", en La dialéctica en suspenso. Fragmentos sobre la historia, Santiago de Chile, ARCIS-LOM, 1995, p. 58.
}

tos que haga emerger como sentido aquello que bajo el cielo de la dominación no puede ser dicho sino distorsionadamente. Una historiografía que, a diferencia del tradicional sintagma de "ir al pasado", reflexione sobre cómo y cuáles pretéritos llegan a nuestro presente, ${ }^{13}$ a través de marcas, indicios, memorias -al modo como Ítalo Calvino pensaba los signos de la historia de Zaira en Las ciudades invisibles-. Que trabaje la cita, a través del comentario, como un encuentro con la palabra pretérita, es decir, con el sujeto, dejando trabajar la distancia en el cruce entre un pasado que expone su solicitud al presente por medio de sorpresivos y fulgurantes momentos de atracción empática, y la reflexión crítica que modula las tareas del rescate de lo sido, pero que está atenta a lo que ese pretérito impone como conmoción por su actualidad. ${ }^{14}$

\section{7} Atender a esos momentos, instantes relampagueantes, en los que la emancipación se ha manifestado con más o menos intensidad, en esta o aquella dimensión de la vida sociocultural y política -incluso en acontecimientos cotidianos y que aparentan ser nimios- requiere, a diferencia de las versiones hegemónicas en que el pasado se postula como cerrado y terminado, que se conciba un pasado abierto, a partir de un vínculo con el presente por el cual se actualicen los futuros pasados inconclusos, latentes, bloqueados pero no completamente eliminados. Abrir el pasado permite pensar la historia más allá del

${ }^{13}$ Georges Didi-Huberman, Ante el tiempo. Historia del arte y anacronismo de las imágenes, Buenos Aires, Adriana Hidalgo, 2006.

${ }^{14}$ Un desarrollo más extenso de este y otros puntos en Roberto Pittaluga, "En torno a los sentidos de "pasarle a la historia el cepillo a contrapelo", en Actas del III Seminario Internacional Políticas de la memoria, Buenos Aires, Centro Cultural "Haroldo Conti", 2010. Disponible en <http://conti.derhuman.jus.gov.ar/2010/10/mesa41/pittaluga_mesa_41.pdf >. 
tiempo lineal, homogéneo y vacío que propone y sostiene la modernidad hegemónica, primer paso para una historiografía alternativa. Al rescatar esos pasados olvidados, elididos, se superpone al tiempo lineal de la continuidad, que es el de la historia de los vencedores, otro tiempo, discontinuo, con el que el presente establece vínculos no cronológicos sino rememorativos. La historia se bifurca en múltiples senderos -como en el cuento borgeano-, y aunque la mayoría ha sido truncada, nos permiten pensar la historia en la pluralidad de sus posibilidades subyacentes y atender a sus contingencias abandonando todo teleologismo. Al rescatar esos pasados olvidados que implicaban otra historia posible, el presente que se siente así interpelado pierde también su consistencia temporal homogénea; deja de ser un presente para pluralizarse en función de los pasados diferenciales que lo interpelan, deja de ubicarse en la cola de una tradición continuista de una historia necesaria para concebirse como instancia agonística de otra posible bifurcación, es decir, puede pensar su propia contingencia y chance emancipatoria.

Los pasados de las bifurcaciones truncadas son los pasados de los vencidos, con los que el presente, por esta elaboración historiográfica e histórica, pasa entonces a establecer un vínculo en la discontinuidad, enlazando segmentos de historias que no se dejan acumular en ninguna versión continuista. Fórmula paradójica: se necesita una historia que construya la tradición de la discontinuidad. Y no otra cosa puede ser, en mi opinión, una historia de la izquierda.

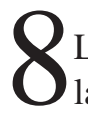
La problemática del tiempo -medular en las luchas por las emancipaciones- sirve también para exponer que esas temporalidades diversas y antagonistas atraviesan la escritura historiográfica, concebida en sentido amplio. No parece posible acometer la tarea de colaborar en esa escritura, dando cuenta de esa complejidad, si la narrativa historiográfica está ella misma atrapada en una concepción de la temporalidad que es la hegemónica del tiempo lineal y continuo, concepción que hace de todo pasado algo cerrado y muerto. $\mathrm{Si}$ una historia de la izquierda es un rescate (en el sentido fuerte del término) de una tradición de luchas, rebeldías e insurgencias, la misma operación historiográfica está marcada por una toma de posición. Una toma de posición que es la que permite inteligibilidades que las tomas de posición hegemónicas en el campo historiográfico y la escritura que allí se practica no posibilitan; toma de posición que, por otra parte, no puede reducirse al punto de vista del historiador o la historiadora en términos individuales, sino que debe ser constituida en la misma "operación historiográfica". Se requiere pensar una forma de escritura que haga justicia a las formas de la emancipación que se resguardan en el nombre "izquierda".

\section{Bibliografía citada}

Benjamin, Walter, "Sobre el concepto de historia" [1940], en La dialéctica en suspenso. Fragmentos sobre la historia, Santiago de Chile, ARCIS-LOM, 1995.

Bobbio, Norberto, Derecha e Izquierda. Razones y significados de una distinción política, Madrid, Taurus, 1995.

D’Alimonte, Roberto, "Espacio político", en Norberto Bobbio, Nicola Matteucci y Gianfranco Pasquino (dirs.), Diccionario de Política, México, Siglo XXI, 1991.

Castelnuovo, Elías, "Los bárbaros están a las puertas de Petrogrado", en La Protesta, 26 de octubre de 1919.

Didi-Huberman, Georges, Ante el tiempo. Historia del arte y anacronismo de las imágenes, Buenos Aires, Adriana Hidalgo, 2006.

- Remontajes del tiempo padecido. El ojo de la historia. 2, Buenos Aires, Biblos, 2015.

Furet, François, "La Francia revolucionaria (17871791)" [1969], en Louis Bergeron, François Furet y Reinhart Koselleck, La época de las revoluciones europeas, 1780-1848, Colección Historia Universal Siglo XXI, vol. 26, México, Siglo XxI, 1976. 
Pittaluga, Roberto, "En torno a los sentidos de 'pasarle a la historia el cepillo a contrapelo", en Actas del III Seminario Internacional Políticas de la memoria, Buenos Aires, Centro Cultural "Haroldo Conti", 2010. Disponible en <http://conti.derhuman.jus.gov.ar/2010/10/mesa41/pittaluga_mesa_41.pdf $>$.

\section{Resumen/Abstract}

\section{Notas para una historia de la izquierda}

Con el objetivo de pensar las historias de las izquierdas, este artículo propone una aproximación a algunos aspectos del término izquierda como concepto político. El autor destaca que tales experiencias, siempre plurales, articulan un componente relacional (vinculado a la escena representativa pero también a la democrática), otro posicional (en tanto expresión de las emancipaciones) y, generalmente, un componente identitario (cristalizaciones en tiempos de despolitización). A su vez, una historia de la izquierda implica una reflexión sobre la propia tarea historiográfica, en la medida en que no puede excluirse de los conflictos históricos que ese concepto nombra.

Palabras clave: Izquierda política - Emancipación Identidad política - Historiografía
, Soviets en Buenos Aires. La izquierda de la Argentina ante la revolución en Rusia, Buenos Aires, Prometeo Libros, 2015.

Trouillot, Michel-Rolph, Silencing the past. Power and the Production of History, Boston, Beacon Press, 1995.

\section{Notes for a history of the Left}

With the aim of thinking about the history of the left, this article proposes an approach to some aspects of the term left as a political concept. The author highlights that such experiences, always plural, articulate a relational component (linked to the representative scene but also to the democratic one), a positional one (as an expression of emancipations) and, generally, an identity component (crystallizations in times of depoliticization). In turn, a history of the left implies a reflection on the historiographical task itself, insofar as it cannot be excluded from the historical conflicts that this concept names.

Keywords: Political left - Emancipation - Political identity - Historiography 